\title{
Construction of cloud learning environment for Open Education: the exploration and practice of Zhuhai Radio \& TV University
}

\author{
Yi Dai ${ }^{1, a}$, Fei Wan ${ }^{2, b}$, Fan $\mathrm{Wu}^{2, \mathrm{c}}$, Hou Han ${ }^{3, \mathrm{~d}}$ \\ ${ }^{1}$ 1. South China Normal University, School of Information Technology In Education, Guangzhou, \\ China \\ ${ }^{2}$ Zhuhai Radio \& TV University, Zhuhai, China \\ ${ }^{3}$ South China Normal University, School of Information Technology In Education, Guangzhou, \\ China

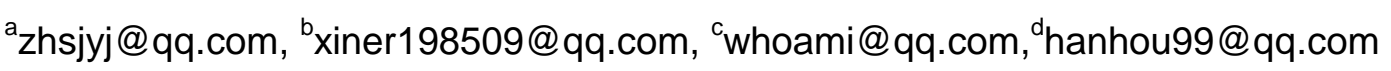

\begin{abstract}
Keywords: Open education; Cloud learning environment; Large-scale streaming media interaction; Learning path; Learning content

Abstract. In order to meet the needs of open education learners, researchers from home and abroad have carry out a lot of research work on the theme of online learning environment. With the continuous development of China's open education, the original online learning environment exposed some shortcomings in aspects like interaction and curriculum management. Based on the application requirements of Open University and the exploration demand of the new teaching model, this paper proposed to design the cloud learning environment from aspects of large-scale streaming media interaction, learning content management and interaction. The cloud learning environment could support effective teaching management, highly interactive teaching and comprehensive teaching evaluation. Through the application research of cloud learning environment in Zhuhai Radio \& TV University, this paper demonstrates the effectiveness of cloud learning environment on teaching mode in innovative open education, and satisfaction of learners' individualized needs.
\end{abstract}

\section{Introduction}

Environment is an ancient proposition affecting human development, and online learning environment is always an important problem in the study of open education. In order to better meet the needs of learners in open education, Radio \& Television University provides an autonomous learning environment for learners, and expands the freedom and learning field of learners through the computer network and communication technology. The three-layer interactive distance learning platform (the Central Radio \& TV University, provincial Radio \& TV University, and prefecture-level Radio \& TV University) has constructed an effective online learning environment which provides video, courseware, forum discussion and real-time chat tools and plays an important role in open education. As the rise of new generation of information technology, such as cloud computing, massive data, mobile Internet, learners put forward new requirements about online learning environment. They have more demands especially for learning content interaction, interaction in process of learning and the support of different ways of learning. As a result, MOOC (massive open online courses) rises and develops rapidly. MOOC can support many terminals, such as PC, iPad, iPhone and Android. This has brought new vitality to the design of the open education online learning environment.

Integration of cloud services and mobile terminals to construct the new teaching environment has become an important issue in the study of open education. Cloud computing provides dynamic, collapsible and virtualized computing resources, and effectively supports massive users concurrent access to open educational resources and services. The application of the mobile terminal in open education provides learning experience anytime or anywhere in need, and meets needs of open education learners' on-the-job learning and fragmentation learning. 


\section{The design of the cloud learning environment}

The wide application of information technology brings many changes for teaching methods, and some scholars analyze from two dimensions of the teaching content delivery way and interactivity, as shown in Figure 1. The teaching content delivery way develops from face-to-face, blended to online delivery and the interaction changes from no interaction to support of highly interaction and collaboration. The main content delivery way of open education is face-to-face and online, from the interactive dimension, and both are in the "low to moderate" level. That is, the face-to-face teaching is still a teacher-centered "typical classroom teaching"; online learning is organized mainly by network institutes. Small class teaching seminars, which support highly interaction and collaboration, and MOOCs are rarely used in open education field. The reason is the lack of learning environment, especially autonomous online learning environment for adult learners.

\begin{tabular}{|c|c|c|c|}
\hline $\begin{array}{l}\text { Highly } \\
\text { interaction and } \\
\text { collaboration }\end{array}$ & $\begin{array}{l}\text { Small-class } \\
\text { teaching } \\
\text { seminars }\end{array}$ & $\begin{array}{l}\text { Active learning/ } \\
\text { Flipped } \\
\text { Classroom }\end{array}$ & $\begin{array}{l}\text { MOOCs } \\
\text { Network institute }\end{array}$ \\
\hline $\begin{array}{l}\text { Low to moderate } \\
\text { interaciton }\end{array}$ & $\begin{array}{l}\text { Typical } \\
\text { classroom } \\
\text { teaching }\end{array}$ & $\begin{array}{l}\text { Face to face } \\
\text { teaching with } \\
\text { some online } \\
\text { activities }\end{array}$ & \\
\hline No interaciton & $\begin{array}{l}\text { Lecture hall } \\
\text { theatre type } \\
\text { teaching }\end{array}$ & $\begin{array}{l}\text { Lecture } \\
\text { assisted with } \\
\text { online video }\end{array}$ & $\begin{array}{l}\text { Early } \\
\text { television } \\
\text { universitv }\end{array}$ \\
\hline
\end{tabular}

Fig. 1 development trend of teaching and learning in the technical background

In order to better adapt to the learning needs of open education learners, on the analysis of features of learners and teaching in open education, this paper proposes the principle that should be followed in cloud learning environment design in the open education.

\section{Supporting highly teaching interaction}

Interaction is the core of teaching, and the learners could meaningful construct knowledge only through interaction ${ }^{[2]}$. In the open education, some scholars divide online interactive teaching activities into teaching interaction and social interaction ${ }^{[3]}$. Interaction needs to reflect the effect of mutual interaction and influence. At least one side of the interaction should be learners. According to the other side of the interaction, teaching interaction in cloud learning environment is divided into: interaction between people and content, and interaction between people.

The interaction between people and the content refers to the interaction between learners and learning content. From the early TV University, network, to today's MOOC, interaction of learning content is gradually strengthened. In early stage of TV university, the main transmission way of learning content is "one-way communication", learners are passive to receive knowledge; teaching content of network school is "static sharing", in which the typical courses include China's exquisite courses, MIT OCW, etc. Although learners have control and initiative of their learning pace, teaching content is still a simple presentation, lack of interaction, and learners are easily tired and absent minded; MOOCs courses organize learning content, take "the short video +interactive practice "as the basic teaching unit, and provide instant feedback for learners with the help of interactive exercises. This can encourage and guide the learners to learn and think more positively ${ }^{[4]}$. However, the feedback information of the interactive exercises in the MOOCs course is relatively easy, which are mainly deterministic feedback (to point out whether learners' answer is correct), answer feedback (to provide correct answers for learners) or retry feedback (to tell learners the answer is incorrect and allow learning again). In addition, learners need delicate feedback like guidance information, or 
learning focus in the next step in learning content interaction, in order to promote deep conceptual understanding of learners ${ }^{[5]}$.

Human interaction refers to the interaction around specific learning problems between teachers and students. With the development of information technology, the human interaction diversifies, including real-time and non-real-time interaction. In real-time interaction, face-to-face communication is still the best way. How to achieve a better effect of online interaction in open education by means of technology under the influence of dispersed learning locations and the growing proportion of learners and teachers? That is a problem for researchers to work on. In the non-real-time interaction, the current online learning platform provides online forums, message boards and other interactive modules, supporting a simple text interaction between learners and teachers. Because of no theme or unclear theme, there is few students' interactive information in course forum, which does not really play the role of non-real-time interaction. A variety of interactive mechanism needs to establish in remote teaching and counseling, such as, two-way video interaction based on massive streaming media technology, friends recommendation based on social network, and all the feedback, consultation and answering, which teachers provide learners in the classroom teaching, will be integrated into teaching contents and learning environment.

\section{supporting effective teaching management}

Because of open courses including excellent courses, MIT OCW、MOOCS and the like, learners could learn high quality teaching resources and obtain knowledge anywhere. But academic certificate education occupies an important position in the open education, and learners should obtain required credits within the prescribed years. Therefore, compared with the MOOCS, online learning environment in open education needs to provide the function of teaching management.

In open education, teaching management involves education information management, learning content management and learning management. The object of education information management is all kinds of data and information related to education management, involving educational institutions, faculty, students, infrastructure, and financial assets. Learning content management service is to create, store, assemble and deliver personalized learning content, based on learning object. Learning management service mainly provides two functions: one is learners and learning activity management, including course registration, student registration and attendance, progress tracking, operation and evaluation, data analysis and report generation; the other is the curriculum management, including course catalog and materials management and schedule. At present, both the network courses and MOOCs courses are carrying on teaching video and resources in single linear order. The relationship between different subjects and subjects with different contents of educational resources has not been defined and used. That means learners can only learn a single teaching resource one by one, and students themselves control the learning order, which may leads to disorientation. Nicosia thinks that network education needs to define a structured curriculum and specific learning path to guide learners ${ }^{[6]}$. Open education online learning environment needs to provide strategies of searching and organizing teaching resources with the learning path for learners; and let learners complete the autonomous learning according to the appropriate learning path, to avoid learning activities deviated and lost in the learning process.

\section{Supporting a comprehensive teaching evaluation}

Teaching evaluation plays an important role in teaching and learning process. Multi-evaluation under the technical support emphasizes the integration of evaluation and teaching, which transfers from static summative evaluation to the dynamic process that attaches much importance on formative assessment and feedback ${ }^{[7]}$. Timely answer 、 evaluation and effect analysis in online learning activities, make learners have an objective and correct evaluation ${ }^{[8]}$, and it also provides the basis for teaching management and decision. The key is to effectively track and evaluate the learning process and effect of open education learners. Because of fragmented and disperse learning data as well as limited single analysis methods ${ }^{[9]}$, existing open curriculum system in China does not effectively monitor the learning process and effect, teaching management department and teachers are still unable to make effective prediction and decision with data in learning process ${ }^{[10]}$. Under the 
background of cloud computing and data development, learning analysis technology has gradually become an indispensable part in education field ${ }^{[11]}$. Online learning platform like MOOC and Khan Academy has done a lot of research in providing learning analysis, tracking data information of academic progress, learning participation and academic achievement of learners, and exploring acquisition and analysis techniques based on data to provide personalized learning support for learners. Open education online learning environment needs to provide the comprehensive support for organizing evaluation activities 、 making the content and data tracking and analysis in learning process.

\section{Supporting multiple terminal applications}

With the arrival of the $3 \mathrm{G} / 4 \mathrm{G}$ era, the learners become more and more dependent on mobile terminal. They use various fragmented time when walking to work and waiting in line to learn what they are interested in. The open education emphasizes on the open in time, place, method and resources ${ }^{[12]}$, and it has been a trend of technological development to construct learning environment supporting multi terminal applications. This brings new challenges to online learning environment design: on one hand, the compatibility of learning resources needs to be improved, across multi terminal release of digital content has become an inevitable trend; on the other hand, massive data processing demand of the center server needs improving. Because the existing server of open education online learning platform can't cope with emergency in bulk processing request, and the open course website faces problems in sudden massive access, such as: slow site access speed, the link cannot be opened. In order to achieve synchronization and interaction of massive video at any time, any place, cloud computing needs to provide powerful back-end processing ability.

\section{Constructing cloud learning environment function}

Based on the analysis of open education demand, according to the design principle of the online learning environment, this paper constructs the cloud learning environment; its structure is shown in Figure 2. Users enter the environment through two ways: through the PC browser to visit the open education website into all kinds of service systems, or through the terminal application access these systems. The unified identity authentication system will verify the legitimacy of learners, teachers and all kinds of users, and integrate user information of all application system through the single enter system. The basic information management system of users functions to maintain user information, manage user organization structure and information related to education and teaching. It could provide relevant information in teaching process for all kinds of application systems. Learning management system is important to support teaching process; it integrates large-scale streaming media interactive services into the process of teaching and learning, and supports the business management, to better support the teaching process. 


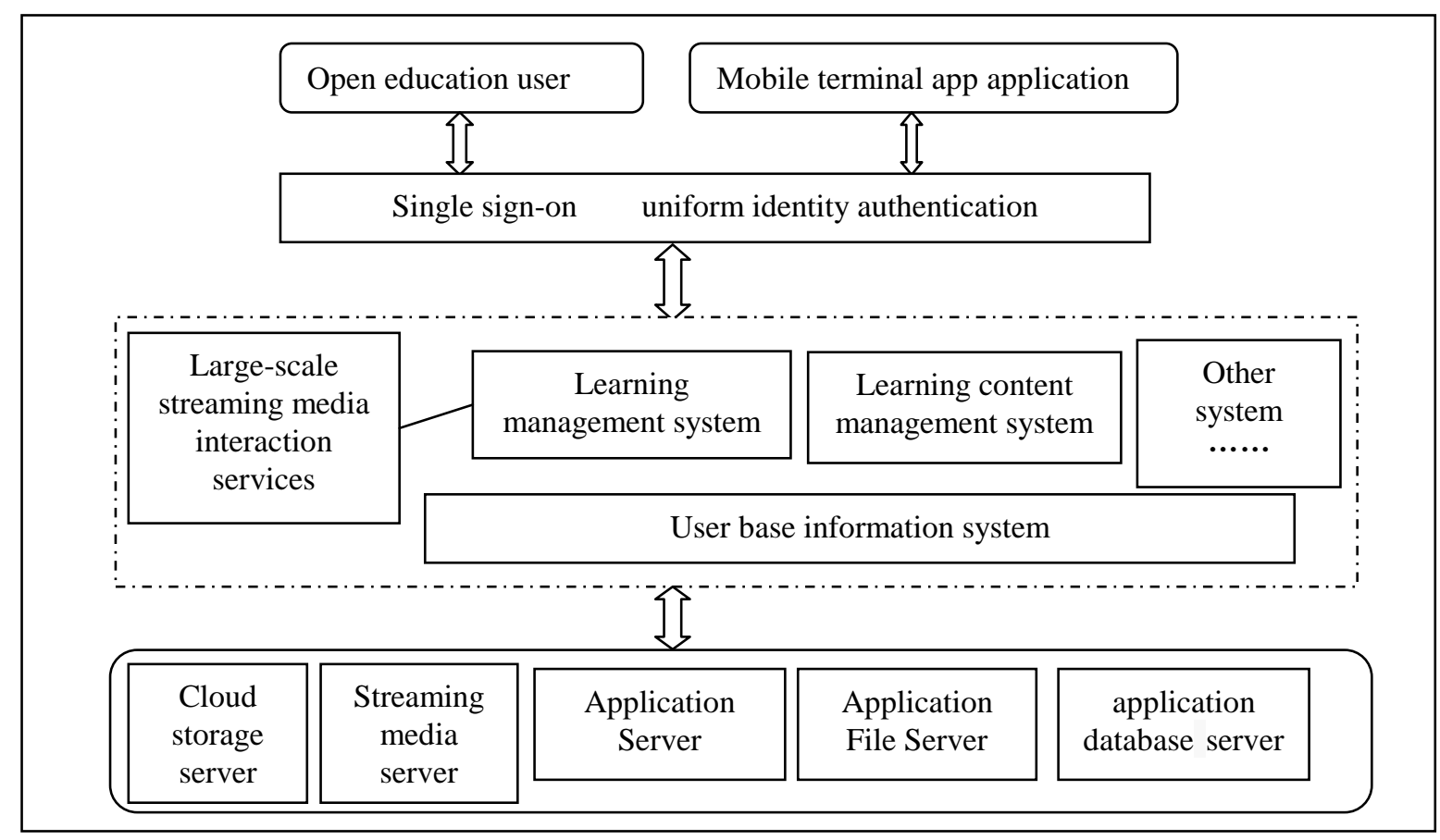

Figure 2 cloud learning environment structure

\section{Learning management system: large-scale streaming media interaction service}

Large-scale streaming media interactive service is a key cloud service in cloud learning environment, conference, course and the curriculum tables are the three core elements. It takes the role of learning management system, and supports online teaching, online training and learning. Its function structure as chart 3 shows.

Online Teaching. Online learning is a kind of application mode of audio and video solution provided by conference room based on large scale streaming media interactive services. The conference room provides rich online interactive functions, including electronic whiteboard, document sharing, collaborative editing, desktop sharing, text chat, private chat and interaction, annotation tool, sharing annotations in order to meet various kinds of interactive needs on situation of remote teaching and discussion mentoring. According to the specific application situations, online teaching can be divided into two applications: live classroom and online project learning. Among them, live classroom applies to teacher centered classroom, all registered learners can watch live; online project learning is mainly the interactive discussion from person to person, for the registered learners. Based on the functions of teaching online, teachers can effectively organize and carry out remote online teaching activities. Distance learners can participate in teaching activities On-the-job, and meanwhile, participate in real-time video and audio interaction with other students through the terminal equipment (pad, PC, etc.) . The teacher can record content in class and share course URL with authorized learners; before class, teacher mails to notice learners to ensure learners can participate in class on time.

Online Training and Learning. "Online training and learning" is a kind of application mode based on large-scale streaming media interactive service curriculum. Its realization of online learning activities of the organization and management functions includes the definition of learning activities, creating and implementation, online learning resource loading and push, online learning process tracing and management (such as interactive learning process record, records of the results of learning, performance statistics etc.). Differences exist between curriculum and curriculum schedule about the types and numbers of associated content. "Curriculum" can only be associated with one resource; "Curriculum schedule" can be associated with multiple resources. In addition, curriculum schedule can also include video conference and courses, and it allows teachers set the learning path between different contents. In other words, in the curriculum design process, teachers can integrate digital learning objects according to the appropriate control strategy, which enables students to learn according to a certain learning path. 
Learning path is composed of a series of ordered nodes; each node corresponds to a learning activity, including learning objects, courses or conferences. Large-scale streaming media interactive service sets the following kinds of node values (Table 1), describing the learning of the node itself, to maintain the learning state value of the learning object. In learning and setting the learning path, cloud learning environment mainly provides three node states: setting state value, learning state value and operating state value. The setting state values mainly serve the course designers; when setting the node for the learning path, the initial state of a node value must be set to "compulsory", "Optional" or "hidden". Learning state value and operating state values mainly serve the learners, the attribute values are influenced by the learning path setting and students' learning situation. For example, when the curriculum designer set the initial node state to "compulsory", if learners finish all required nodes before, the learning state node value they see is "in" and operation state values as "open"; after students learning this node, the learning state value is "passed", the operation state value as "revision ". Taking the course "Computer Application Foundation" in Zhuhai Radio \& TV University as an example, figure 4 shows the relationship between contents of excel part in the course. Teachers can set the relationship between compulsory and elective learning content, and the relationship between follow-up and the previous learning content.

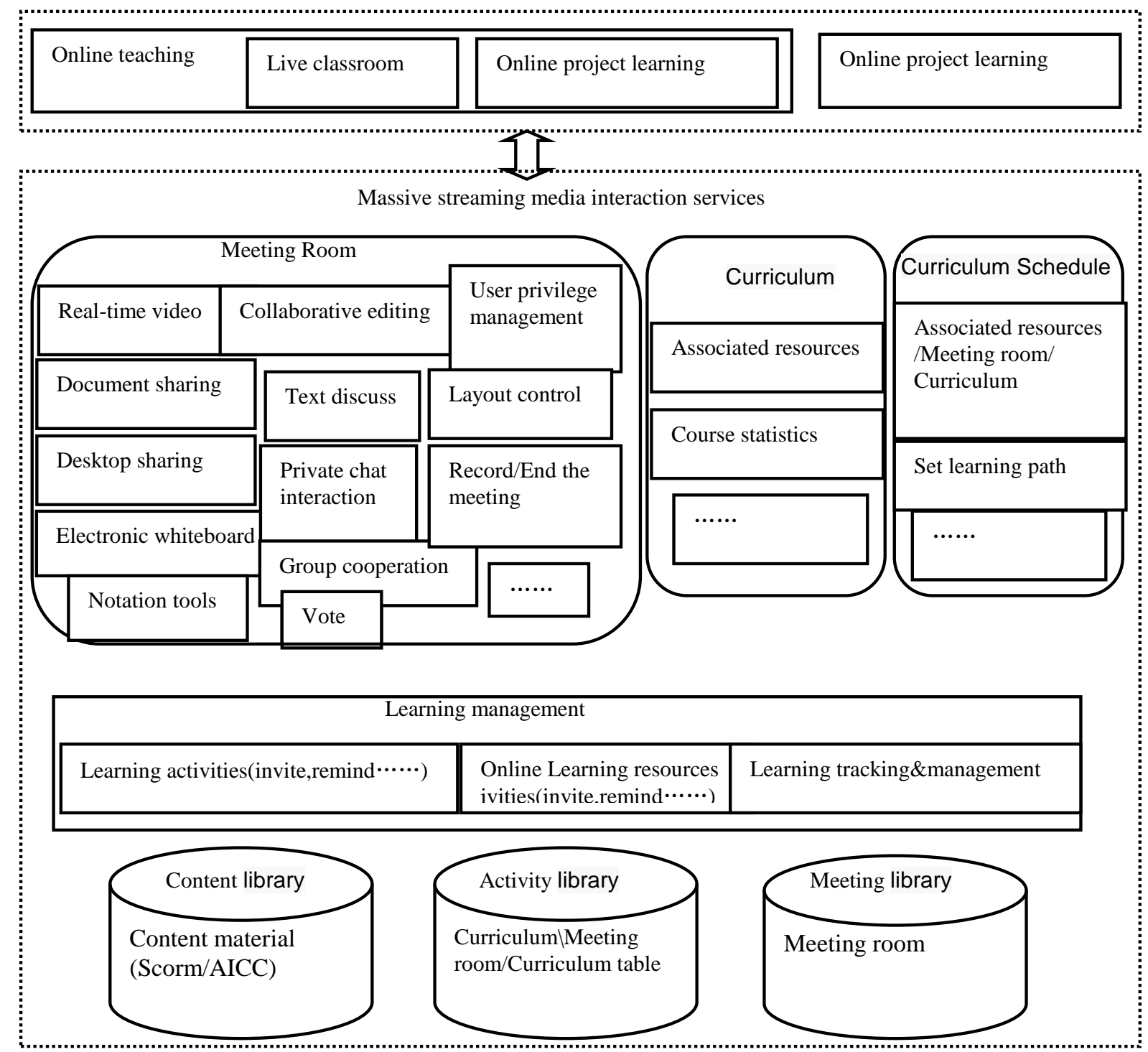

Figure 3 Large scale streaming media interactive services 
Table 1 Learning path node state value

\begin{tabular}{|l|l|l|l|}
\hline $\begin{array}{l}\text { Set the state } \\
\text { value }\end{array}$ & $\begin{array}{l}\text { Compulsory } \\
\text { courses }\end{array}$ & Optional course & hidden \\
\hline \multirow{2}{*}{$\begin{array}{l}\text { Learning state } \\
\text { value }\end{array}$} & already passed & In process & Not pass \\
\cline { 2 - 4 } & Required & Not required & locked \\
\cline { 2 - 4 } & $\begin{array}{l}\text { Introduction } \\
\text { project }\end{array}$ & $/$ & $/$ \\
\hline $\begin{array}{l}\text { Operating } \\
\text { state value }\end{array}$ & Open & Review & Continue \\
\hline
\end{tabular}

Based on learning path set by the teachers, learners from different regions of the world can be asynchronous; according to their own working time and state, the system can automatically record the learning process, learning state and learning effect of the learners. This mode is not only convenient for the management of teachers, but also an effective solution to the current contradictions between work and learning problems that open education learners are facing.

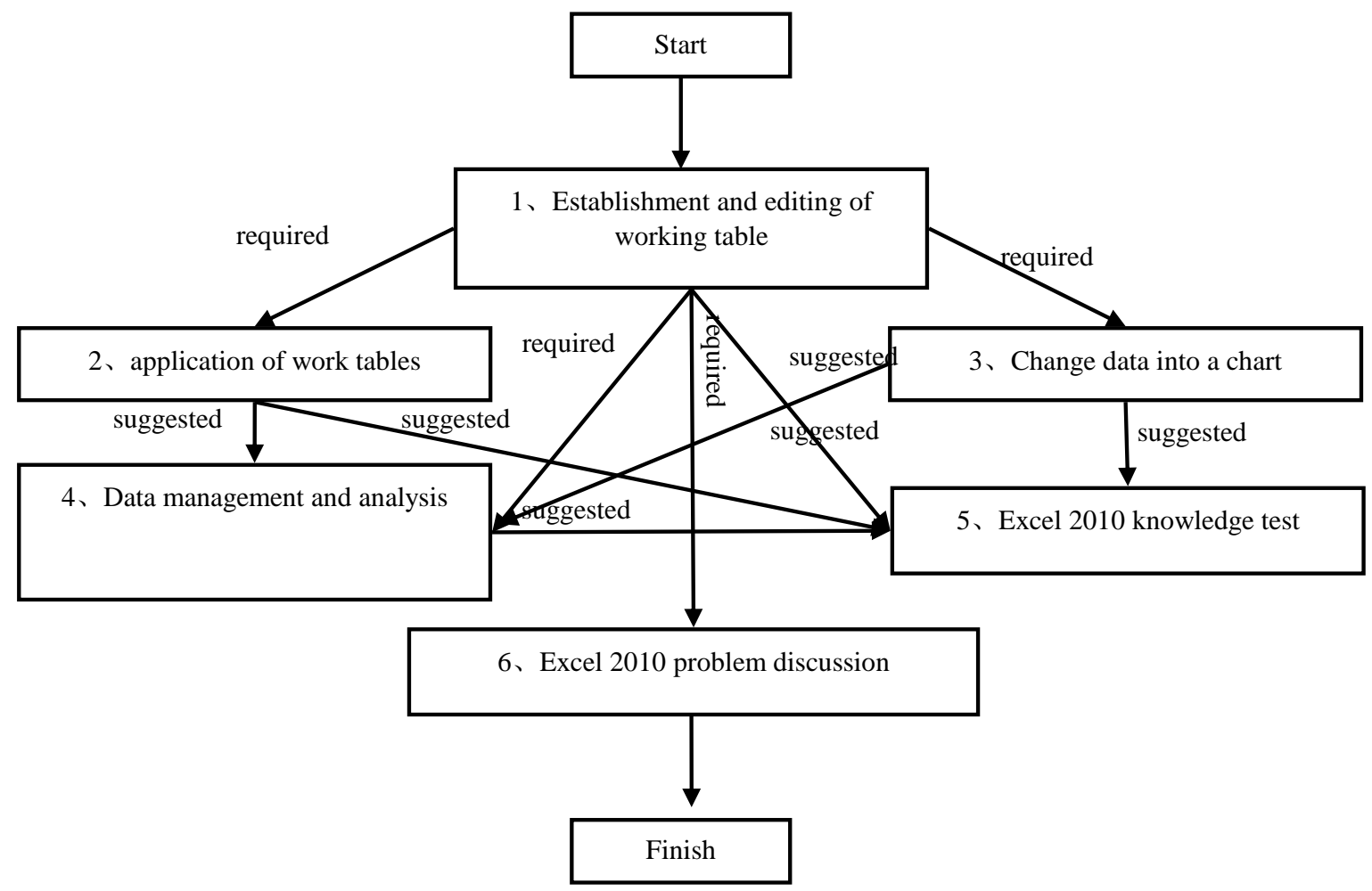

Figure 4 Teacher learning path Settings

\section{Learning content management}

The quality of the learning content and feedback has important effect on learners' learning effect of open education. Cloud learning environment provides an open and shared learning content management system for teachers, as well as content security for large-scale streaming media interaction. Figure 6 shows the relationship between the three kinds of education service (learning content management system, learning management system, and education information management system) and subject application. Learning content for digital learning object LO (Learning Object) as a unit, LO is a reusable component of a course , such as text documents, PowerPoint documents, pictures, videos or SCORM courseware and test paper. All learning objects of learning content management system can be packaged of learning resources with AICC or SCORM standard, and then imported into the learning management system, to support teaching and learning. 


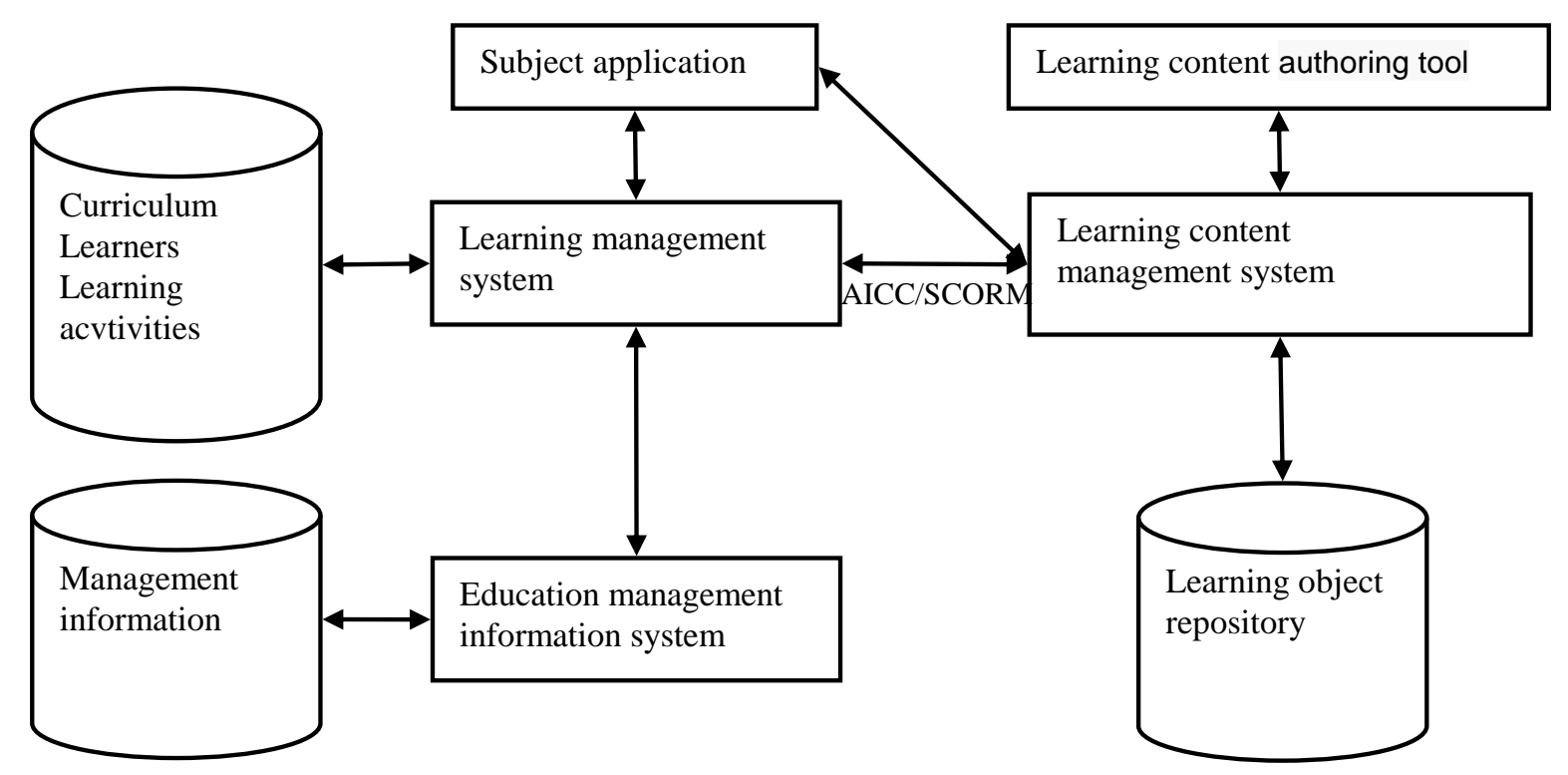

Figure 5 The relationship between three kinds of education service and the subject application

Learning content authoring tool is an important part of learning content management; interactive learning content production has a number of tools, such as Camtasia studio. Considering the integration application of learning content and large-scale streaming media interactive service, the learning content authoring tool in this paper is Adobe presenter and Adobe Captivate.

Adobe Presenter has many functions, such as: recording, screen recording, camera capture, editing and managing test questions and embedding multimedia animation. As the PowerPoint plug-in, Presenter can set the PowerPoint file of interactive animation and questions to be released to web page or Zip compressed file with SCORM/AICC standard. Upload the generated Zip compressed file to the learning content management system, and relate it to a course in large-scale streaming media service, the online evaluation, timely feedback, performance statistics and recording function can be realized. Taking "Computer Application Foundation" in Zhuhai Radio \& Television University as an example, Figure 7 shows the learners' test results in Excel knowledge test.

\begin{tabular}{|c|c|c|c|c|c|}
\hline Order & Question & $\begin{array}{l}\text { Right } \\
\text { answer number }\end{array}$ & $\begin{array}{c}\text { Wrong } \\
\text { answer number }\end{array}$ & Accuracy Rate & Score \\
\hline 1 & $\begin{array}{l}\text { Through the "fill" in the "edit" menu command, } \\
\text { which of the following cannot be generated? }\end{array}$ & 33 & 3 & 92 & 10 \\
\hline 2 & $\begin{array}{l}\text { In Excel, all of the input file data and calculation } \\
\text { is done through the }() ?\end{array}$ & 21 & 15 & 58 & 10 \\
\hline 3 & $\begin{array}{l}\text { The following types of statistics in the chart } \\
\text { ( ) is with the } \mathrm{X} \text { axis and } \mathrm{Y} \text { axis is? }\end{array}$ & 17 & 15 & 53 & 10 \\
\hline 4 & $\begin{array}{l}\text { In the four steps of the chart wizard making the } \\
\text { statistical charts, the first step is to }()\end{array}$ & 20 & 12 & 63 & 10 \\
\hline 5 & $\begin{array}{l}\text { If you want to know the average of } \mathrm{B} 2, \mathrm{~B} 3, \mathrm{~B} 4 \text {, } \\
\text { formula should be ( ) }\end{array}$ & 15 & 14 & 52 & 20 \\
\hline
\end{tabular}

Figure 6 Test response analysis (in accordance with the analysis of the test questions)

Concepts related to tests in the Presenter include: quiz, question group, and question, the relationship among them is shown in "quizl" and "quiz2"in figure 6. Presenter supports choice, judgment, short answer, fill in the blanks, attachment, sorting, rating scale and hot issues. When designing tests, the teacher first need to create a quiz, in which the smallest unit is question, teachers can choose to use the question group to classify similar problems. According to Xu Qian's classification of teaching feedback ${ }^{[13]}$, teachers can set up the parameters of quiz, question group and question in Presenter, and provide the following feedback for students:

Retry Feedback. It tells learner incorrect or failed, allowing the learner to answer the question/quiz again until the answer is right. 
Corrective Feedback. It provides information for students' specific error or misunderstanding. Informative Feedback. When the learners did not pass the quiz/ question group or questions, it will jump to a position inside teaching resources (as Figure 7 below) or open external resources for learners to learn, but not directly giving the correct answer.

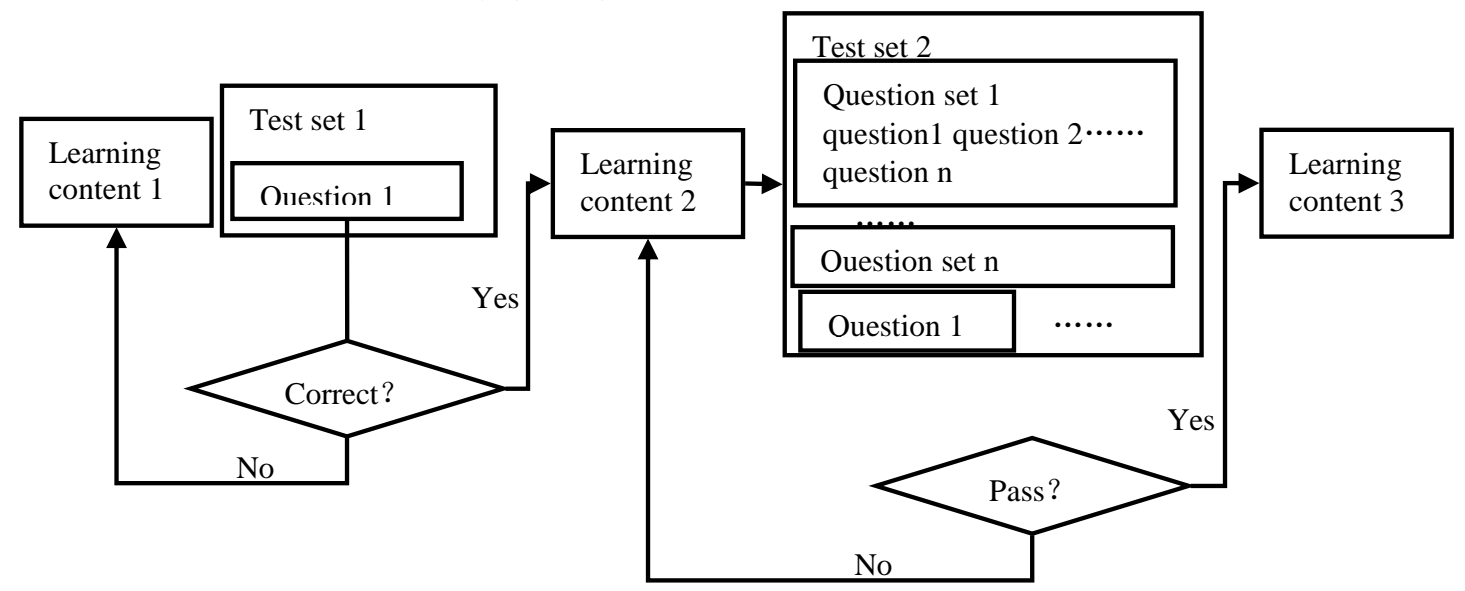

Figure 7 Presenter interactive content settings schematic diagram

Adobe captivate has similar function with the presenter in interactive content production. In addition, Adobe Captivate can record the operation steps of computer or application software, according to different teaching purposes, teachers can choose modes like software simulation demonstration, software simulation guide or software simulation assessment to make Micro class of software operation or skills training.

\section{Individual learning space}

With the development of information technology, the open source movement brings more convenience to the learners, and learners can get more resources. However, learners tend to be confused when facing too many resources. Cloud learning environment, through ways of social networks, users subscription and experts' recommendation, provides an interactive communication space and personalized learning resources for learners. Firstly, learners can concern with a teacher or a special topic, when their contents updated, and learners can automatically get resources from the system. In the learning process, the content that learners collect, download, browse, will automatically be together and gradually form a "learning portfolio", to facilitate the learners to review timely of learning content. Secondly, learners can form "learning circles" by label subscription. In the" learning circle" learners can share video or data, carry out online seminar, discuss with each other, thus, to enhance their learning effect. At the same time, the "learning circle" provides "private communication" function, the contents of a private letter are only visible by the two, and it's easy for users to save private information with friends. Application of private letter expands the space to exchange and discuss between learners, and between learners and teachers. When learners are puzzled watching video lessons, they can communicate with the teacher in a private letter, to realize asynchronous answering.

On foundation of large-scale streaming media interaction service, learning content management and diversified ways of interactive communication, cloud learning environment can achieve the core features of MOOC, that is " short video + interactive practice + interactive communication +learning data", making it possible for the construction of MOOC courses in open education, table 2 summarizes how the cloud learning environment achieve MOOC features . 
Table 2 MOOC technical characteristics compared with the cloud learning environment implementation

\begin{tabular}{|c|c|c|}
\hline classification & MOOC Characteristics & cloud learning environment implementation \\
\hline \multirow{2}{*}{$\begin{array}{l}\text { People interact } \\
\text { with content }\end{array}$} & $\begin{array}{l}\text { short video\& interactive } \\
\text { practice }\end{array}$ & \multirow{2}{*}{$\begin{array}{l}\text { Organize interactive learning content through } \\
\text { Presenter/Captivate (short video\& interactive practice }) \text {, and } \\
\text { provide users with a variety of feedback (Figure 6) }\end{array}$} \\
\hline & Immediate feedback & \\
\hline $\begin{array}{l}\text { People interact } \\
\text { with people }\end{array}$ & interaction & $\begin{array}{l}\text { Combine non real-time interaction based on social network } \\
\text { (circle, labels, DMS, etc.) with real-time interactive services } \\
\text { based on mass media streaming }\end{array}$ \\
\hline $\begin{array}{l}\text { Teaching } \\
\text { evaluation }\end{array}$ & Learning big data & $\begin{array}{l}\text { track learners learning progress and analyze learning } \\
\text { performance based on massive streaming media interaction } \\
\text { services and learning content }\end{array}$ \\
\hline $\begin{array}{l}\text { Teaching } \\
\text { management }\end{array}$ & / & $\begin{array}{l}\text { Provide teaching information management, learning content } \\
\text { management and learning management, in the service of formal } \\
\text { schooling education service }\end{array}$ \\
\hline
\end{tabular}

\section{Application research of cloud learning environment}

To understand the application effect of cloud learning environment in open education, since September 2014, the author of this paper has carried out application test and effect evaluation in Zhuhai Radio \& TV University.

First, select 2 professional subjects of computer network and e-commerce, 2 teachers, 156 students in 4 classes to carry out a one-semester application research of cloud learning environment. The two teachers developed 53 interactive learning content based on their courses "basic computer application" and "e-commerce management", organized 19 online teaching activities and answering activities, formed 15 online training courses (Curriculum) . Learners used a variety of terminal access to the cloud learning environment for online learning; teachers organized learners to carry on online teaching, communication and discussion through large-scale streaming media service. After one semester, the author made a questionnaire to the students participating in the application test and interviewed the teachers. Among them, $86.3 \%$ of the students think that cloud learning environment is helpful to course learning, $84.9 \%$ of them think that cloud learning environment relieves their contradiction of working and learning, $73.9 \%$ are willing to apply this environmental application to other courses.

Secondly, in order to expand the scope of application of cloud learning environment, at the beginning of March 2015, based on the effectiveness made in the first two pilot classes, the author organized other 39 teachers from Zhuhai Radio \& TV University to carry out cloud learning environment application training, and investigated these teachers using the questionnaire after training. It means to know their acceptance of the cloud learning environment, and the survey results are shown in Table 3. From table 3, we could see the acceptance mean value of function usability, usefulness, behavior intention and security conditions of cloud learning environment is above 3.5. Between "general" and "consent", teachers are in favor of "agree", which shows that teachers in Zhuhai Radio \& TV University are generally in relatively high acceptance of cloud learning environment. 
Table 3 The mean value of teachers' acceptance of the cloud learning environment

\begin{tabular}{|c|c|c|c|}
\hline classification & Description & Mean value & $\begin{array}{l}\text { Total mean } \\
\text { value }\end{array}$ \\
\hline \multirow{2}{*}{$\begin{array}{l}\text { Perceived } \\
\text { usability }\end{array}$} & Interface is easy to understand\&operate & 3.73 & \multirow[t]{2}{*}{3.8} \\
\hline & I could skillfully use each function of the cloud leanring environment & 3.97 & \\
\hline \multirow{6}{*}{$\begin{array}{l}\text { Perceived } \\
\text { usefulness }\end{array}$} & enrich the interaction forms of online learning & 4.09 & \multirow[t]{6}{*}{3.96} \\
\hline & strengthen the monitoring of students learning process & 4.05 & \\
\hline & Promote my teaching mode innovation & 4 & \\
\hline & Support for students' individualized learning & 3.91 & \\
\hline & Improve my teaching skills & 3.86 & \\
\hline & Improve my ability of teaching innovation & 3.86 & \\
\hline \multirow[t]{2}{*}{ behavior intention } & It's necessary to use the cloud learning environment in teaching & 3.86 & \multirow[t]{2}{*}{3.82} \\
\hline & I will use the cloud learning environment in my future teaching & 3.77 & \\
\hline \multirow[t]{2}{*}{$\begin{array}{l}\text { guarantee } \\
\text { conditions }\end{array}$} & $\begin{array}{l}\text { I hope to have technical personnel and experienced teacher to provide } \\
\text { help for me }\end{array}$ & 4.5 & \multirow[t]{2}{*}{4.23} \\
\hline & I hope to get the encourage and support from leaders and colleagues & 3.95 & \\
\hline
\end{tabular}

* 5 "strongly agree", 4 for "agree", 3 is "general", 2 as "not agree", 1 "totally disagree"

Follow-up, the author will deepen the research on the application of cloud learning environment from two aspects of horizontal and vertical. Vertically, the author will summarize early research and quantify the quality of learning that cloud learning environment to students' learning in open education ; Horizontally, the author will expand the scope of application of the cloud application environment, and plan to amplify 4 professions, 8 teachers, 16 classes, and continue to explore application mode and approach of cloud learning environment.

\section{Conclusions}

Based on the construction of cloud computing, massive data and mobile Internet technology, cloud learning environment can solute many problems well in online learning of open education, such as lack of teaching interaction, learning ways, especially the sharp contradiction between working and learning in open education. Our research is still in the initial stage of practice. Later we will continue to create a series of online courses in the cloud learning environment, guiding students to learn independently in the environment, and constantly improve the function of learning environment in teaching practice, explore application model to form cloud learning environment, and build digital learning environment and service system of effective open education .

\section{Acknowledgements}

This work was financially supported by the Major Projects of Guangdong Province Science and Technology(No.[2012]99), Zhuhai Education Research Projects(2014D0401990065).

\section{References}

[1] Pong T.C. The Changing Landscape of E-learning, 2013.

[2] Craig Chaudron. Second language classrooms: Research on teaching and learning[M]. Cambridge University Press, 1988.

[3] Hongmei Li. Discussion on distance education online interactive teaching activities [J]. Journal of guangxi radio and TV university, 4,006. (2014)

[4] Maosong Sun. The basic characteristics of MOOC and its development trend, 2013. 
[5] Robert L Bangert-Drowns, Chen-Lin C Kulik, James A Kulik. The instructional effect of feedback in test-like events[J]. Review of Educational Research, 1991, 61(2): 213-238.

[6] Mirko Cesarini, Mattia Monga, Roberto Tedesco. Carrying on the e-learning process with a workflow management engine[C]. ACM, 2004:940-945.

[7] Jun $\mathrm{Xu}$, Lianzhang Tang. Exploration of education informatization under cloud computing and big data era [J]. Education information technology, 2014, (249): 3-9.

[8] Songbo Li. Teaching resources research based on cloud computing platform [J]. The contemporary vocational education, 2012, (8): 28-30.

[9] Yanyan Li, Shaoqian Ma, Ronghuai Huang. Study analysis technology, serving learning process design and optimization [J]. Open education research, 2012, 18(5): 20.

[10]Lei Zhao, Hong Zhu. The study for the network open courses [J]. Journal of jiangsu Open University, 2014, 25(4): 38-43.

[11]Craig Bach. Learning analytics: Targeting instruction, curricula and student support[J]. Proceedings EISTA, 2010,

[12]Zhijian Yang. National Open University construction: reform and innovation [J]. China distance education, 2013, 4: 5-10.

[13] Qian Xu, Lihua XU. Foreign research on teaching feedback and enlightenment [J]. Journal of contemporary education science, 2010, (007): 27-31. 